\title{
AMPEROMETRIC METHOD FOR THE DETERMINATION OF PROPANIL IN A SIMULATED RICE FIELD ENVIRONMENT
}

\author{
N. PRIYANTHA*, A. NAVARATNE, D.A. JAYAWICKRAMA and U.S.K. \\ WELIWEGAMAGE \\ Department of Chemistry, University of Peradeniya, Peradeniya.
}

(Received: 18 April 2003 ; accepted: 01 September 2003)

\begin{abstract}
Amperometric experiments conducted with commercial samples of Propanil at Fe(III)TPPCl-modified glassy carbon electrodes in $1: 3 \mathrm{CH}_{3} \mathrm{CN} / \mathrm{H}_{2} \mathrm{O}$ result in smooth amperograms producing linear calibration curves. The amount of Propanil present in effluent water leached through soil of a model rice cultivation in a polytunnel can be accurately determined using this method. The concentration of Propanil in water samples collected within a period of $8 \mathrm{~h}$ decreased from $(6.70 \pm$ $0.06) \times 10^{-3} \mathrm{~mol} \mathrm{dm}^{-3}$ to $(8.10 \pm 0.08) \times 10^{-5} \mathrm{~mol} \mathrm{dm}^{-3}$. No detectable levels of Propanil were found in samples obtained after $8 \mathrm{~h}$ within the capability of the method. A preconcentration step that had potential to further enhance the sensitivity and decrease the lower detection limit of electrochemical detection of Propanil was also investigated.
\end{abstract}

Key words: Amperometry, electrochemical detection, pesticide, Propanil, rice cultivation.

Electrochemical detection finds widespread applications in the determination of simple, inorganic cations and anions, ${ }^{1-3}$ as well as complex organic substances, including many pesticides. ${ }^{4-6}$ Electroanalytical techniques provide unique advantages for the determination of analytes of interest due to their excellent detection capabilities with relatively low-cost instrumentation. Consequently, they can compete with other modern detection systems, which require expensive instrumentation. Depending on the desired limit of detection, one can conveniently use a method of choice among many electrochemical techniques, from voltammetry which is sensitive in the $10^{-3} \mathrm{~mol} \mathrm{dm}^{-3}$ to $10^{-4} \mathrm{~mol} \mathrm{dm}^{-3}$ range, to stripping analysis which is able to detect even at $10^{-9} \mathrm{~mol} \mathrm{dm}^{-3}$ levels. ${ }^{7,8}$

Although electrochemical methods were traditionally employed for the detection of electroactive substances, this situation has now changed with the introduction of catalytic methods. Since the activity of a catalyst is specific for a molecule or a class of molecules, selection of an appropriate electrocatalyst may be the most demanding task. Heterogeneous electrocatalysis, where the catalyst is usually in the solid phase, as an external thin coating on the surface of bare electrodes, ${ }^{9,10}$ or alternatively, by incorporating the catalyst to the bulk of a solid electrode for intimate contact, has been attractive. ${ }^{11,12}$ In the earlier situation, the stability of the catalyst can be improved by introducing electroinactive, stabilizing

${ }^{*}$ Corresponding author 
agents into the coating. ${ }^{13}$ In many instances, the substance of interest has been made electroactive at the potential at which the catalyst is reduced/oxidized, qualifying for the catalytic-electrochemical-chemical (catalytic EC) mechanism. ${ }^{14,15}$

Electrochemical detection, however, has its limitations, especially in real sample analysis, where undesirable matrix effects offset the actual result. This situation has been successfully addressed when electrochemical detection is performed after liquid chromatographic separation (i.e., liquid chromatography in conjunction with electrochemistry or LCEC). ${ }^{16-18}$ Detection of some pesticides at low levels by reversed phase LCEC methods has been recently reported. ${ }^{19-21}$ Nevertheless, with most cases, which involve real analysis, a prior clean-up step would be highly desirable. Furthermore, necessity of large amounts of organic solvents, and economical factors have limited further advancement of such methods.

In this research, we report an amperometric method, based on the catalytic electrochemistry of 5,10,15,20-tetraphenylporphyrinatoiron(III) chloride, for the detection of Propanil, a heavily used herbicide on rice, in a simulated rice cultivation environment, where Propanil-contaminated water is leached out from a model rice bed after application of the recommended dose of this pesticide. When Propanil is applied to the crop, a fraction of it is absorbed into soil, and subsequently leaches out and may reach ground and surface water resources. Propanil and its principal metabolic degradate, 3,4-dichloroaniline (3,4-DPA) are the residues of concern for drinking water risk assessment. ${ }^{22-24}$ Therefore, understanding of the fate of Propanil in the environment is of considerable interest, and the simulated rice bed used in this research would be an ideal model to study this aspect. Further, this study mimics the real environmental analysis of Propanil by an electroanalytical method based on electrocatalysis.

\section{METHODS AND MATERIALS}

A commercial sample of Propanil (Mackwoods Marunil, 36\% 3,4-DPA) was purchased from the local market, which was used throughout all experiments without any purification. Analytical grade $\mathrm{KCl}, 5,10,15,20$-tetraphenylporphyrinatoiron(III) chloride [Fe(III)TPPCl], and HPLC grade $\mathrm{CH}_{3} \mathrm{CN}$ and $\mathrm{CH}_{2} \mathrm{Cl}_{2}$ were purchased from Aldrich, USA. All the solutions were prepared using distilled deionized water, and the standard solutions were prepared daily.

A $10 \mathrm{~cm}^{3}$ solution of the Fe(III)TPPCl catalyst was prepared, and glassy carbon (GC) electrodes were modified with the catalyst according to the procedure published elsewhere. ${ }^{25}$

Instrumentation: A CV-1B cyclic voltammograph and an X-Y recorder, both purchased from Bioanalytical Systems Inc., USA, were used for all cyclic voltammetric and amperometric experiments. The three-electrode cell consisted of 
a bare or Fe(III)TPPCl-modified GC working electrode, a platinum counter electrode and a saturated calomel reference electrode (SCE). All potentials were reported with respect to $\mathrm{SCE}$, and all experiments were conducted under $\mathrm{N}_{2}$ saturated conditions.

Preparation of rice cultivation and collection of samples for analysis: A model rice bed was constructed in a polytunnel (Figure 1a), about $0.5 \mathrm{~m}$ above ground level, using a flat-bottomed aluminum basin of dimensions $2.0 \mathrm{~m} \times 1.0 \mathrm{~m}$ and $0.5 \mathrm{~m}$ in height. The bed was filled with paddy field soil, which was free of any pesticides, up to a height of $15 \mathrm{~cm}$. Outlet tubes with taps were fitted at the bottom of the bed to collect water. A cross-section of the bed is shown in Figure $1 \mathrm{~b}$.

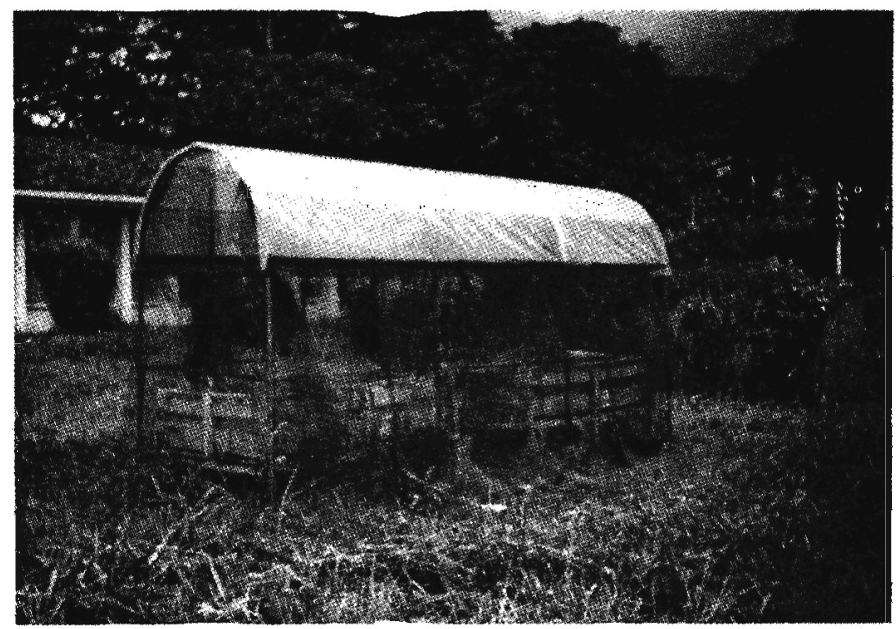

(a)

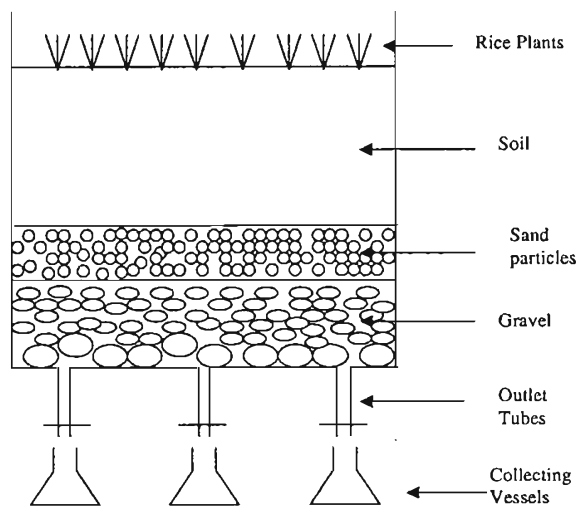

(b)

Figure 1: (a) A picture of the model rice bed prepared in the polytunnel and (b) Schematic representation of the cross-section of the model rice bed. 
Rice plants grown in a nursery up to an age of $25 \mathrm{~d}$ were transplanted in the bed. Echinochloa and other weed species were also allowed to grow together with rice (Figure 2). The spraying solution of Propanil was prepared in water according to the published guidelines, giving a final concentration of approximately $0.0314 \mathrm{~mol} \mathrm{dm}{ }^{-3} \cdot{ }^{26}$ The solution was sprayed evenly on weeds after $12 \mathrm{~d}$ of transplanting. The field was well drained out before the herbicide was sprayed in order to expose weeds.

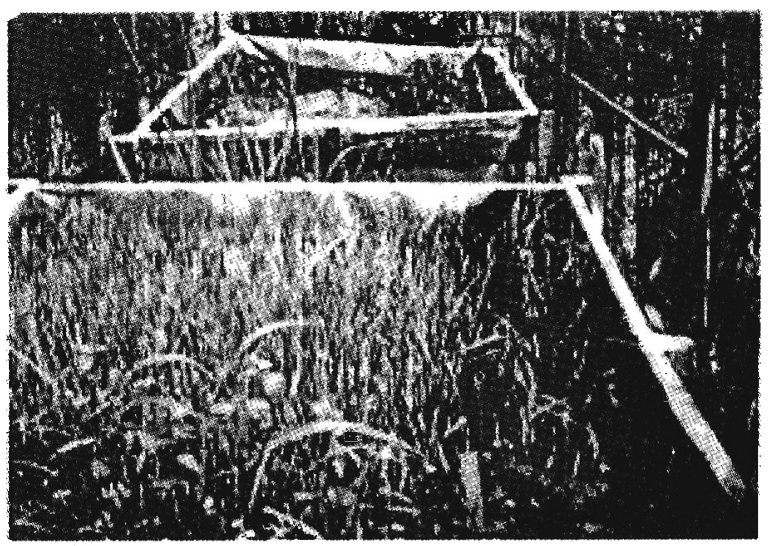

Figure 2: Rice cultivation in the model rice bed.

After $3 \mathrm{~d}$ of pesticide introduction, the bed was watered up to a level of 2.0 $\mathrm{cm}$, and water drained through soil was collected at the bottom at time intervals of $0.00 \mathrm{~h}, 0.50 \mathrm{~h}, 1.00 \mathrm{~h}, 2.00 \mathrm{~h}, 4.00 \mathrm{~h}, 6.00 \mathrm{~h}$ and $8.00 \mathrm{~h}$.

Electrochemical detection of Propanil: A stock solution of $5.0 \times 10^{-3} \mathrm{~mol} \mathrm{dm}^{-3}$ Propanil was prepared in $0.1 \mathrm{~mol} \mathrm{dm} \mathrm{d}^{-3} \mathrm{KCl}$ using the commercial formulation, and dilutions were made to prepare standard solutions of $1.0 \times 10^{-3} \mathrm{~mol} \mathrm{dm}^{-3}$ and $5.0 \times 10^{-4} \mathrm{~mol}$ $\mathrm{dm}^{-3}$. The solvent composition of $1: 3 \mathrm{CH}_{3} \mathrm{CN} / \mathrm{H}_{2} \mathrm{O}$ was always used to maintain adequate solubility of Propanil.

Water samples collected from the rice bed were initially filtered to remove any solid particles. Aliquots of $0.5 \mathrm{~cm}^{3}$ of the filtered effluent were then introduced to the $10.00 \mathrm{~cm}^{3}$ electrolyte solution, and amperometric current responses were recorded for quantification of Propanil.

Preconcentration of leachates: A volume of $1 \mathrm{dm}^{3}$ standard solution of Propanil of $1.0 \times 10^{-6} \mathrm{~mol} \mathrm{dm}^{-3}$ concentration was prepared in distilled water. It was passed through a column packed with silica gel $60\left(230-400\right.$ mesh) at a flow rate of $5 \mathrm{~cm}^{3}$ $\mathrm{min}^{-1}$. The column was then flushed with $100 \mathrm{~cm}^{3}$ of $5 \%$ ethanol:acetone, and the eluent was evaporated to dryness. The dry residue was dissolved in $2 \mathrm{~cm}^{3}$ of $1: 3$ $\mathrm{CH}_{3} \mathrm{CN} / \mathrm{H}_{2} \mathrm{O}$, and tested amperometrically for Propanil. 


\section{RESULTS AND DISCUSSION}

\section{Development of the method}

A catalytic wave was observed for the reduction of Propanil at the Fe(III)TPPClmodified GC electrode at a potential of $-0.3 \mathrm{~V}$, as expected. ${ }^{25}$ Amperometric responses obtained under optimized experimental conditions at this potential are shown in Figure 3, where each step corresponds to a successive addition of $0.2 \mathrm{~cm}^{3}$ of $5 \times 10^{-3} \mathrm{~mol} \mathrm{dm}^{-3}$ Propanil standard solution.

As reported earlier, the electrochemical response of this sensor is based on the catalytic EC mechanism, which involves the reductive dehalogenation of the carbon -chlorine bond of Propanil, forming an adduct with the reduced form of the metalloporhyrin, [Fe(II)TPP]. ${ }^{14}$ This reduced form of the metalloporphyrin, produced in-situ, is the active form of the catalyst. The stable form, Fe(III)TPPCl, is believed to be regenerated together with the decomposition of the adduct, as the last step of the reaction.

Direct proportionality between the bulk concentration of Propanil in the solution and the corresponding amperometric current generated at the electrode surface is the analytically useful aspect of this detection scheme. This enables the determination of the concentration of Propanil in water samples, leached out from the soil in the rice bed. Another important feature of the sensor is that its electrocatalytic response mechanism, based on the $\mathrm{C}-\mathrm{Cl}$ bond cleavage, allows the reduction of 3,4-dichloroaniline, the principal degradate of Propanil, at the same operational potential. Thus, the determination of the total Propanil concentration, Propanil in its molecular form and in the form of 3,4-dichloroaniline, is possible with this method. The analytical result obtained through amperometric calibration curves would therefore account for any 3,4-dichloroanilne, decomposed in the soil under the simulated conditions employed.

Amperograms reported in Figure 3 produce nonlinear calibration curves, as shown in Figure 4, which is a typical result in many amperometric analyses, in particular at chemically modified electrodes. This can be attributed to many factors, such as limited mass transfer through the coating, and loading the coating with the analyte and/or its products. These factors would complicate diffusion characteristics of the analyte toward the electrode surface. Although increase in convective mass transfer is one option to mitigate this issue, it usually produces noisy amperograms, which subsequentially yields erroneous results at low concentrations. A logical solution to this problem would be the decrease in the concentration of the standard solution used for sequential additions of Propanil.

The calibration curve of the amperogram obtained with sequential additions of $0.2 \mathrm{~cm}^{3}$ of $5.0 \times 10^{-4} \mathrm{~mol} \mathrm{dm}^{-3}$ standard solution of Propanil is shown in Figure 5 . 


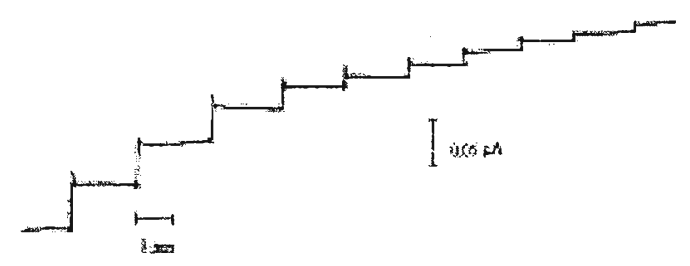

Figure 3: Steady-state amperometric responses for Propanil at $\mathrm{Fe}$ (III)TPPCl-modified GC electrode at $-0.30 \mathrm{~V}$ in $1: 3 \mathrm{CH}_{3} \mathrm{CN} / \mathrm{H}_{2} \mathrm{O}$ under $\mathrm{N}_{2}$ saturated with concentration increments of $8.0 \times 10^{-5} \mathrm{~mol} \mathrm{dm}^{-3}$.

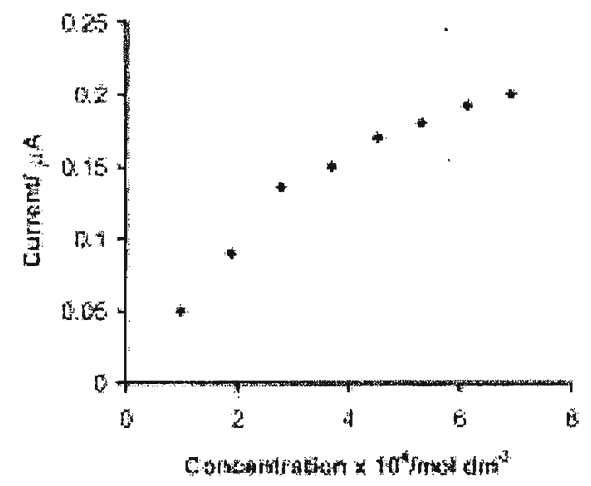

Figure 4: Calibration curve for the amperogram shown in Figure 3.

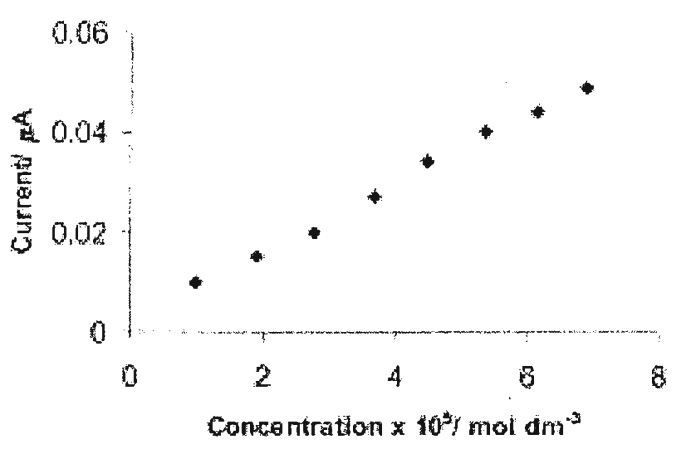

Figure 5: Calibration curve for the steady- state amperometric responses for Propanil at Fe(III)TPPCl-modified GC electrode at - $0.30 \mathrm{~V}$ in $1: 3 \mathrm{CH}_{3} \mathrm{CN} /$ $\mathrm{H}_{2} \mathrm{O}$ under $\mathrm{N}_{2}$ saturated with concentration increments of $1.0 \times 10^{-5} \mathrm{~mol}$ $\mathbf{d m}^{-3}$.

This calibration curve can be expressed in the linear form of $i=0.0068 C+0.0023$ (where $i$ is the amperometric current in $\mu \mathrm{A}$ and $C$ is the bulk concentration of Propanil in the $10^{-5} \mathrm{~mol} \mathrm{dm}^{-3} \mathrm{scale}$ ), with a regression coefficient $\left(R^{2}\right)$ of 0.9957 , 
which clearly shows the linearity of the curve. The sensitivity of detection, and the minimum detection limit based on the signal-to-noise $(S / N)$ ratio of three, have been determined to be $0.0068 \mu \mathrm{A} \mathrm{mol}^{-1} \mathrm{dm}^{3}$ and $1.0 \times 10^{-5} \mathrm{~mol} \mathrm{dm}^{-3}$, respectively. The linear dynamic range of the proposed detection is $(1.0-6.9) \times 10^{-5} \mathrm{~mol} \mathrm{dm}^{-3}$, which suggests that Propanil present in aqueous medium within these limits can be detected with high accuracy.

As indicated earlier, a small positive intercept of $0.0023 \mu \mathrm{A}$ is associated with the calibration curve. This can be attributed to the background current at the potential of $-0.3 \mathrm{~V}$. However, it is not necessary to do background correction as the concentrations can directly be obtained from the calibration curve.

\section{Analysis of effluent water}

The water leached out from the model rice bed, after application of Propanil on rice cultivation, was collected at regular intervals, as stated in the Experimental section. When these Propanil-contaminated water samples were introduced to the electrochemical cell, amperometric currents were generated at $-0.3 \mathrm{~V}$, at which elecrtrocatalytic reduction of Propanil and 3,4-dichloroaniline occurs. Eight samples were taken at each time from different locations of the rice bed, and each sample was analyzed in triplicate using the amperometric method developed. Concentration of Propanil for each trial was determined by the calibration curve shown in Figure 5 , and the Q-test at $95 \%$ confidence level was applied to reject any outlying results. The average total concentration of Propanil of the effluent water collected at each time, and the associated standard deviation are given in Table 1 . The low standard deviation is indicative of high precision of the amperometric method.

Table 1: Concentration of Propanil in soil-leached effluent watèr collected from the model rice bed at different time intervals.

\begin{tabular}{|c|c|}
\hline Time/h & Concentration $/ \mathrm{mol} \mathrm{dm}^{-3}$ \\
\hline 0.00 & $(6.70 \pm 0.06) \times 10^{-3}$ \\
\hline 0.50 & $(5.32 \pm 0.05) \times 10^{-3}$ \\
\hline 1.00 & $(3.40 \pm 0.05) \times 10^{-3}$ \\
\hline 2.00 & $(1.61 \pm 0.05) \times 10^{-3}$ \\
\hline 4.00 & $(7.53 \pm 0.07) \times 10^{-4}$ \\
\hline 6.00 & $(3.50 \pm 0.09) \times 10^{-4}$ \\
\hline 8.00 & $(8.10 \pm 0.08) \times 10^{-5}$ \\
\hline
\end{tabular}

According to Table 1, there is a decreasing pattern of the concentration of Propanil with time, as expected. Additionally, Propanil was not detected in the 
samples collected after $8 \mathrm{~h}$. This could be due to the fact that the concentration of Propanil in these samples is below the minimum detection limit of the amperometric method. The importance of these results is that they demonstrate applicability of a rapid electrochemical technique for the analysis of effluent water for pesticide pollution.

\section{Preconcentration method}

Amperometry provides excellent detection technology, which is not incorporated with any preconcentration step prior to analysis. The sensitivity of amperometric detection can be further enhanced by conjunction with a suitable preconcentration step. Although chromatographic methods such as GC and HPLC can be coupled with electrochemical detection, the use of such techniques would lead to increase in the cost of analysis.

During this study, the concept of preconcentration was demonstrated using a simple column chromatographic experiment. A solution of $1.0 \times 10^{-6} \mathrm{~mol} \mathrm{dm}^{-3}$ Propanil was undetectable using the amperometric method alone. This solution was successfully preconcentrated, and possibly cleaned-up by passing it through a silica gel packed column, followed by evaporation to dryness. According to the amperometric determination, the final solution prepared from the dry residue showed a concentration of $3.7 \times 10^{-4} \mathrm{~mol} \mathrm{dm}^{-3}$, with a percent recovery of $74 \%$. The concentration of this solution has been increased by a factor of 370, suggesting that Propanil-contaminated water of concentrations well below the lower detection limit of the amperometric method be accurately detected, if this preconcentration method is employed.

The importance of this preconcentration step is its simplicity and low-cost. The efficiency of this method can be enhanced, by optimizing the solvent system, flow rate and the sorbent. In order to enhance the percent recovery further, washing the column with more solvent may be recommended.

\section{Conclusions}

As the method developed was based on a catalytic process specific for organochlorines, no interference problems were expected from other types of substances unlike with bare electrodes, under the conditions used for amperometry, except from other organo-chlrorine pesticides in the sample.

In order to justify this argument, the effluent water drained out from the rice bed, before introduction of Propanil, was tested in a similar manner. The rice field water did not produce any significant amperometric response, indicating that other constituents of the soil-leached water would not lead to any interference in the detection of Propanil. 
Applicability of an electrocatalytic detection scheme based on Fe(III)TPPCl for the detection of Propanil in water samples leached out from soil in a simulated rice bed is demonstrated in this study. This rice bed provides an ideal microenvironment to understand the fate of Propanil after it is sprayed on rice cultivation. These results could mimic the levels of the pesticide present in largescale rice fields. As the run off and leach out of this pesticide into ground water and surface water pose a serious health hazard, this type of investigation would be important to create baseline data, as well as to monitor Propanil residues and its degraded products, mainly 3,4-DPA, the major residue of Propanil, in the total environment.

\section{Acknowledgement}

Financial assistance from the National Science Foundation (NSF) for the grant RG/99/C/06 is gratefully acknowledged. Valuable suggestions provided by Dr. G.K. Manuweera, Registrar of Pesticides, Department of Agriculture, are highly appreciated.

\section{References}

1 Frant M. (1994). History of the early commercialization of ion selective electrodes. Analyst 119: 2293.

2 Saterlay A.J., Ford J.S. \& Compton R.G. (1999). Sono-cathodic stripping voltammetry of manganese at a boron-doped diamond electrode: application to the determination of manganese in instant tea. Analyst 124: 1791-1796.

3 Jin J., Xu F. \& Miwa T. (2000). Square wave cathodic stripping voltammetry of ultratrace manganese in the presence of ultrasound irradiation. Analytical Sciences 16: 317-319.

Mendez J.H., Martinez R.C. \& Martin J.S. (1986). Simultaneous polarographic determination of Parathion and Paraoxon. Catalytic hydrolysis of Parathion by Palladium(II). Analytical Chemistry 58: 1969-1972.

5 Fernandez C., Reviejo A.J. \& Pingarron J.M. (1995). Development of graphitepoly(tetrafluoroethylene) composite electrodes, voltammetric determination of the herbicides thiram and disulfiram. Analytica Chimica Acta 305: 192199.

6 Kroger S., Turner A.P.F., Mosbach K. \& Haupt K. (1999). Imprinted polymer based sensor system for herbicides using differential pulse voltammetry on screen-printed electrodes. Analytical Chemistry 71: 3698-3702. 
7 Pascuel C.B. \& Vincente-Beckett V.A. (1989). Electrochemistry of triphenyltinacetate at a mercury film glassy carbon electrode. Analytica Chimica Acta 224: 97-108.

8 Prabu H.G. \& Manisankar P. (1994). Determination of endosulfan by stripping voltammetry. Analyst 119: 1862-1872.

9 Buttry D.A. \& Anson F.C. (1984). New strategies for electrocatalysis at polymer coated electrodes. Journal of the American Chemical Society 106: 59-64.

10 Wang J. \& Golden T. (1989). Metaloporphyrin chemically modified glassy carbon electrodes as catalytic voltammetric sensors. Analytica Chimica Acta 217: 343-351.

11 Navaratne A. \& Richnitz G.A. (1992). Use of tin oxide electrodes in flow injection analysis with application to plant tissue based biosensors. Analytical Letters 25: 191-203.

12 Wang J. \& Lin Y. (1994). Electrocatalytic flow detection of amino acids at ruthenium dioxide modified carbon electrodes. Electroanalysis 6: 125-129.

13 Root D.P. \& Priyantha N. (1988). Electroinactive coatings on platinum electrodes in aqueous solution. Journal of Electroanalytical Chemistry 257: 231-237.

14 Root D.P., Pitz G. \& Priyantha N. (1991). Electrocatalytic metalloporphyrin electrode for the determination of organohalides. Electrochimica Acta 36: 855-858.

15 Priyantha N. \& Ekanayake H. (1998). Selective electrocatalysis of bromobenzoic acids by 5,10, 15, 20-tetraphenylporpyrinatoiron (III) chloride. Ceylon Journal of Science: Physical Sciences 5: 21-27.

16 Park G.B., Koss R.F., O’Nell S.K., Palace G.P. \& Edelson J. (1981). Determination of sulfinalol hydrochloride in human plasma and urine by liquid chromatography with amperometric detection. Analytical Chemistry 53: 604-606.

17 Zadii J.M., Mitchell R. \& Kuwana T. (1990). Glassy carbon microband electrochemical detector for high performance liquid chromatography. Electroanalysis 2: 209-215. 
18 Baldwin R.P. \& Thomsen K.N. (1991). Chemically modified electrodes in liquid chromatography detection - A review. Talanta 38: 1-16.

19 Selvka C.M. \& Krull I.S. (1987). Liquid chromatography-photolysis electrochemical detection for organoiodides. Analytical Chemistry 59: 17661770 .

20 Martinez, R.C., Rodriguez E., Gonzalo M.G., Jimenz G., Pinto C.G., Pavon J.L.P. \& Mendez J.H. (1996). Determination of fungicides folpet, captan and captafol by cloud-point preconcentration and high performance liquid chromatography with electrochemical detection. Journal of Chromatography A 754: 851.

21 Galeanodiaz T., Guiberteaucabanillas A., Moradiez N., Parrillavazquez P. \& Salinaslopez F. (2000). Rapid and sensitive determination of 4-nitrophenol, 3-methyl-4-nitrophenol, 4,6-dinitro-O-cresol, Parathion-methyl, Fenitrothion and Parathion-ethyl by liquid chromatography with electrochemical detection, Journal of Agricultural and Food Chemistry 48: 4508-4513.

22 Von Nehrin Q.G., Hightower J.W. \& Anderson J.L. (1986). Liquid chromatography with electrochemical detection and coulometric investigations of carbamate and urea pesticides. Analytical Chemistry 58: 2777-2781.

23 Gilliom R.J., Barbash J.E., Kolpin D.W. \& Larson S.J. (1999). Testing water quality for environmental pollution. Environmental Science and Technology 33: $164 \mathrm{~A}-169 \mathrm{~A}$.

24 http:www.pestlaw.comlx/fedreg/2002/EPA-2002.

25 Priyantha N. \& Weerabahu D. (1996). Amperometric Sensor for Propanil. Analytica Chimica Acta 320: 263-268.

26 The Pesticide recommendations (1997). Department of Agriculture, Sri Lanka. 